\title{
A self-correcting method for the measurement of free calcium and magnesium concentrations by ${ }^{1} \mathrm{H}$ NMR
}

\author{
Matthew Wallace, ${ }^{*}$ Thomas Hicks, Yaroslav Z. Khimyak and Jesús Angulo \\ School of Pharmacy, University of East Anglia, Norwich Research Park, Norwich, NR4 7TJ, UK
}

\begin{abstract}
A method for the direct measurement of free $\mathrm{Ca}^{2+}$ and $\mathrm{Mg}^{2+}$ concentrations in the range 1-100 mM by NMR spectroscopy is demonstrated. The method automatically corrects for the effect of ionic strength on the activity of the species in solution and works satisfactorily even when significant concentrations of competitive ions are present. The method requires only the measurement of the ${ }^{1} \mathrm{H}$ chemical shifts of our reporter ligands, glycolate and sulfoacetate, and is easily implemented using NMR imaging techniques. As proof of concept, we extract the thermodynamic binding constants and conformer distributions of analyte ligands using an in situ ion gradient. Existing approaches for the measurement of free $\mathrm{Ca}^{2+}$ or $\mathrm{Mg}^{2+}$ concentrations by NMR operate only at very low ion concentrations or else require careful recalibration for different sample conditions. By providing the free $\mathrm{Ca}^{2+}$ or $\mathrm{Mg}^{2+}$ concentrations, the proposed methodology significantly enhances the information obtainable via NMR investigations of ionresponsive

systems.
\end{abstract}

Calcium and magnesium play an important role in many processes of interest across the physical, biological and environmental sciences. Examples include the formation of gels upon the addition of $\mathrm{Ca}^{2+}$ to solutions of biopolymers ${ }^{1,2}$ or the binding of metals to humic acids in the soil. ${ }^{3}$ While solution-state NMR spectroscopy is a useful technique to study these processes, it is often desirable to also measure the concentration of free $\mathrm{Ca}^{2+}$ or $\mathrm{Mg}^{2+}$ ions in a sample. When complexing species are present, the concentration of free ions can be very different to the total concentrations of $\mathrm{Ca}$ or $\mathrm{Mg}$. The free ion concentrations thus grant valuable insight into the ionresponsive behavior of the systems. ${ }^{4,5}$ The free ion concentrations can be measured using electrochemical probes ${ }^{5-7}$ or fluorescent dyes. ${ }^{8-10}$ However, such measurements can be expensive and inconvenient to perform in addition to NMR, particularly when only limited quantities of sample are available. Furthermore, the insertion of electrodes can cause serious damage to soft-solid samples such as gels while electrochemical methods are also wholly unsuited to study the internal ion gradients that can occur in these systems. ${ }^{11,12}$ Methods for the direct measurement of free $\mathrm{Ca}^{2+}$ and $\mathrm{Mg}^{2+}$ concentrations by NMR are thus required.

Work to date has been confined largely to the analysis of tissues and biological fluids. Strongly chelating ligands such as EDTA or BAPTA typically exhibit slow exchange on the NMR timescale between the free and complexed states. Separate ligand resonances are observed for each coordinating metal ion allowing their concentrations to be measured by integration ${ }^{13-15}$ or saturation-transfer approaches, ${ }^{16}$ provided the total metal ion concentration is less than the total concentration of ligand. The low dissociation constants of such ligands $\left(<2 \mu \mathrm{M}\right.$ for $\mathrm{Ca} 5,5^{\prime}$-Difluoro $\left.\mathrm{BAPTA}^{15}\right)$ restricts the measurement of the free ion concentration to sub-millimolar levels. Elsewhere, native chelating cellular components such as ATP allow the in situ measurement of the free $\mathrm{Mg}^{2+}$ con- centration by ${ }^{31} \mathrm{P}$ NMR. ${ }^{17-21}$ However, these methods are not directly applicable to other systems of interest, for example biopolymer gels, where the metal ion concentrations, $\mathrm{pH}$ and ionic strengths can be very different to physiological conditions. ${ }^{22,23}$ Herein, we demonstrate a method which allows the direct measurement of the free $\mathrm{Ca}^{2+}$ or $\mathrm{Mg}^{2+}$ concentration between $1-100 \mathrm{mM}$ by ${ }^{1} \mathrm{H} \mathrm{NMR}$; a concentration range that is of interest for many systems. Our method also self-corrects for the effect of ionic strength, allowing accurate measurements even in samples of unknown ionic composition.

Our method requires only the measurement of the ${ }^{1} \mathrm{H}$ chemical shifts of two reporter ligands, glycolate and sulfoacetate (SFA), rather than the integrals of their resonances and is thus very simple to implement. The method can be readily applied using chemical shift imaging techniques where absolute quantification by integration or heteronuclear NMR measurements are particularly inconvenient. ${ }^{24}$ As proof of concept, we demonstrate the measurement of ligand $\mathrm{Ca}^{2+}$ and $\mathrm{Mg}^{2+}$ binding constants and conformer distributions using chemical shift imaging approaches. We also demonstrate how our method allows the quantification of the free $\mathrm{Ca}^{2+}$ and $\mathrm{Mg}^{2+}$ concentrations in the presence of a complexing ligand. Excellent concordance with literature data is obtained in all cases.

\section{EXPERIMENTAL}

Materials. All reagents were purchased from Sigma Aldrich or Fisher and used as received. $\mathrm{CaCl}_{2}$ and $\mathrm{MgCl}_{2}$ stock solutions used in the indicator calibration experiments were prepared from $1.00 \mathrm{M}$ volumetric solutions (Honeywell). Stock solutions of ligands and were prepared as their $\mathrm{Na}^{+}$salts and stored in HDPE vials. Milli-Q water (18.2 M $\Omega . \mathrm{cm})$ was used throughout the study. 
Preparation of stock solutions. A stock solution of indicator ligands was prepared containing $50 \mathrm{mM}$ sodium glycolate, sulfoacetate (SFA), ethane-1,2-disulfonate (EDS) and potassium methanedisulfonate (KDS). Sodium pyruvate was also tested as an indicator ligand but was freshly prepared before use to avoid microbial degradation. A solution of 2,6-lutidine $(50 \mathrm{mM}), \mathrm{NaOH}(0.1 \mathrm{M})$ and methylammonium chloride $(0.1$ $\mathrm{M})$ was prepared to allow the in situ measurement of $\mathrm{pH}$ by NMR following our published methodology. ${ }^{25}$ The low binding constants of these nitrogen bases permits their use as $\mathrm{pH}$ indicators in the presence of $\mathrm{M}^{2+}{ }^{26,27}$ A solution of DMSO (1 vol\%), methanol (1 vol\%) and 2,2-dimethyl-2-silapentane-5sulfonate (DSS, $20 \mathrm{mM}$ ) was prepared to provide internal chemical shift referencing.

Standard concentrations. Unless otherwise stated, the concentrations of species used in all experiments is as follows: For $\mathrm{M}=\mathrm{Ca}$; indicator ligands $(0.1 \mathrm{mM}$ w.r.t. glycolate $), \mathrm{pH}$ indicator compounds $(0.1 \mathrm{mM}$ w.r.t. methylammonium), reference compounds $(0.001$ vol\% w.r.t. DMSO). For $\mathrm{M}=\mathrm{Mg}$; indicator ligands $(0.05 \mathrm{mM}$ w.r.t. glycolate), $\mathrm{pH}$ indicator compounds $(0.05 \mathrm{mM}$ w.r.t. methylammonium), reference compounds $(0.001$ vol\% w.r.t. DMSO). For NMR imaging experiments $(\mathrm{Ca}, \mathrm{Mg})$; test ligands $(0.2 \mathrm{mM})$, indicator ligands (0.2 mM w.r.t. glycolate), $\mathrm{pH}$ indicator compounds $(0.2 \mathrm{mM}$ w.r.t. methylammonium), and reference compounds $(0.002$ vol\% w.r.t. DMSO).

Calibration of $\mathrm{M}^{2+}$ indicator ligands. To obtain the parameters of the indicator ligands (Table 1), solutions were prepared from the stock solutions described above at concentrations of $\mathrm{MCl}_{2}$ ranging from 0 to $100 \mathrm{mM}$. The low concentration of indicator ligands allows the binding of $\mathrm{M}^{2+}$ to these species to be ignored as the total concentration of $\mathrm{M}^{2+}$ bound to the ligands will be negligible $(<0.1 \mathrm{mM})$. Any $\mathrm{CO}_{2}$ absorption by the solutions during the titrations will have a negligible effect due to the low concentration of base present. The $\mathrm{pH}$ was $\geq 8$ in all calibration samples indicating negligible $\mathrm{CO}_{2}$ absorption or $\mathrm{M}^{2+}$ hydrolysis. We note that the indicator ligands can be used at much higher concentrations $(10 \mathrm{mM})$ although depletion of the free $\mathrm{M}^{2+}$ concentration due to complexation does take place (Figure S-9).

The free $\mathrm{Ca}^{2+}$ concentration was calculated from the total concentration of $\mathrm{CaCl}_{2}$ assuming a $\log \left(\mathrm{K}_{0}\right)$ for the $\mathrm{Ca}-\mathrm{Cl}$ ion pair of $0.41^{27}$ using Equation S-1 in the Supporting Information, correcting $\mathrm{K}_{\mathrm{M}}$ for ionic strength using Equations 5 and 7. The free $\mathrm{Mg}^{2+}$ concentration was set equal to the total concentration of $\mathrm{MgCl}_{2}$ added as the indicator chemical shifts were found to be invariant of the choice of $\mathrm{Mg}^{2+}$ counterion; the indicator ligands cannot distinguish between free $\mathrm{Mg}^{2+}$ ions and weak ion pairs (Section S-1). We attribute this observation to differences in the hydration of $\mathrm{Ca}^{2+}$ and $\mathrm{Mg}^{2+}$ ions (Figure $\mathrm{S}-25){ }^{28,29}$

Creation of $\mathrm{M}^{2+}$ gradients for analysis by NMR imaging. To establish an $\mathrm{M}^{2+}$ gradient in a standard $5 \mathrm{~mm}$ NMR tube, either 4-6 mg of $\mathrm{CaCl}_{2} \cdot 2 \mathrm{H}_{2} \mathrm{O}$ or $7-9 \mathrm{mg}$ of $\mathrm{MgCl}_{2} \cdot 6 \mathrm{H}_{2} \mathrm{O}$ was weighed directly into the NMR tube. Four, $2 \mathrm{~mm}$ diameter glass beads (Karl Hecht, Germany) were placed on top of the salt. For the determination of the ligand binding constants, a solution was prepared containing $0.2 \mathrm{mM}$ sodium L-lactate, maleate, malonate, L-tartrate. Pyromellitate $(0.2 \mathrm{mM})$ was analysed separately from the other ligands. To determine the conformer distributions of malate, a solution was prepared containing sodium $\mathrm{DL}_{-m a l a t e}(10 \mathrm{mM})$, glycolate $(1 \mathrm{mM})$, SFA $(1 \mathrm{mM})$, Tris(hydroxymethyl)aminomethane ${ }^{26}(0.1 \mathrm{mM})$, me- thylammonium $(0.1 \mathrm{mM})$ and DSS $(0.1 \mathrm{mM})$. The $\mathrm{pH}$ was adjusted to 10.5 using $\mathrm{NaOH}$. The solutions were carefully placed on top of the beads using a 9" Pasteur pipette to a height of $40 \mathrm{~mm}$ from the base of the NMR tube. The beads served to prevent excessive mixing of the solution with the salt. The samples were transferred to the NMR instrument for analysis immediately after preparation. The time at which the optimum $\mathrm{M}^{2+}$ gradient became established could be predicted as described in previous work (Section S-2). ${ }^{25}$

NMR. 1D spectra were performed on a Bruker Avance III 500 $\mathrm{MHz}$ spectrometer operating at $500.21 \mathrm{MHz}$ for ${ }^{1} \mathrm{H}$. The probe was equipped with $\mathrm{Z}$-axis pulsed field gradients. ${ }^{1} \mathrm{H}$ spectra were acquired using a double-echo excitation sculpting sequence (Bruker library ZGESGP). $4 \mathrm{~ms}$ Gaussian pulses of $300 \mathrm{~Hz}$ peak power were applied to selectively suppress the $\mathrm{H}_{2} \mathrm{O}$ resonance. Spectra were acquired in $32(\mathrm{Ca})$ or $64(\mathrm{Mg})$ scans with a $15 \mathrm{ppm}$ sweep width and a $4.3 \mathrm{~s}$ acquisition time. Spectra were processed with $128 \mathrm{~K}$ of datapoints and a line broadening factor of $1 \mathrm{~Hz}$. Chemical shift imaging experiments were recorded on a Bruker Avance I Spectrometer operating at $499.69 \mathrm{MHz}\left({ }^{1} \mathrm{H}\right)$. The temperature of both instruments was set at $298 \mathrm{~K}$, calibrated using a methanol standard. ${ }^{30}$ The temperature can be assumed accurate to $0.5 \mathrm{~K}$. The variation in the temperature with time is less than $0.1 \mathrm{~K}$ on both instruments. The method is tolerant of $\pm 1 \mathrm{~K}$ variations in the set temperature of the instrument (Figure S-3).

For the determination of the ligand binding constants, ${ }^{1} \mathrm{H}$ chemical shift images were acquired using a gradient phase encoding sequence based on that of Trigo-Mouriño et al. ${ }^{31}$ and incorporating a double-echo excitation sculpting sequence for water suppression. Gaussian pulses of $4 \mathrm{~ms}$ duration and 300 $\mathrm{Hz}$ peak power were applied to selectively suppress the $\mathrm{H}_{2} \mathrm{O}$ resonance. The phase encoding gradient pulses were in the form of smoothed squares and were of $238 \mu$ s duration. Their amplitude was varied from -27 to $27 \mathrm{G} / \mathrm{cm}$ in 128 steps giving a theoretical spatial resolution of $0.2 \mathrm{~mm} .12$ scans were recorded at each gradient increment giving a total acquisition time of 30 minutes. The signal acquisition time was set at $1 \mathrm{~s}$ and a spoil gradient $(27 \mathrm{G} / \mathrm{cm})$ was employed at the end of the acquisition period to destroy any remaining transverse magnetization. 16 dummy scans were collected prior to signal acquisition. For the determination of the conformer distribution of malate, an analogous sequence was used that employed the perfect-echo WATERGATE sequence of Adams et $a l^{32}$ incorporating the double echo W5 sequence of Liu et $a l^{33}$. The signal acquisition time was set at $2 \mathrm{~s}$ and 8 scans were acquired at each gradient increment giving a total acquisition time of 37 minutes.

No $\mathrm{D}_{2} \mathrm{O}$ was included in any of the samples to allow the direct comparison of binding constant data obtained by NMR with literature values. ${ }^{34-36}$ All samples were thus run off-lock. The performance of the method is not affected significantly by the presence of $10 \mathrm{vol} \% \mathrm{D}_{2} \mathrm{O}$ that may be added to aid shimming (Section S-4). However, the limiting chemical shifts of the indicators are affected slightly and an alternative set of indicator parameters is required for optimum accuracy. For larger fractions of $\mathrm{D}_{2} \mathrm{O}$, a recalibration of the indicator ligands is recommended.

NMR data was processed in Bruker Topspin 3.5. DSS was used as the reference for all spectra $(0 \mathrm{ppm})$. The other reference compounds listed above give equivalent results and equivalent calibration data is provided in the supporting information (Section S-5). Images were processed in phase- 
sensitive mode as described in Reference 31 with $32 \mathrm{~K}$ points and an exponential line broadening factor of 0.3 (malate) and 1 (other ligands). Chemical shifts were extracted from the images using automation scripts written in house. J-couplings were extracted directly from the line separations by Lorentzian deconvolution of the spectra; couplings obtained by spectral simulation were found to agree within $0.1 \mathrm{~Hz}$. Data was exported to Microsoft Excel and non-linear regression performed using the Solver module. ${ }^{37}$ The free $\mathrm{M}^{2+}$ concentrations and $\gamma_{2}$ in the imaging experiments were obtained from Equations 9 and 10 (malate) and 3 and 8 (other ligands). To obtain binding constants, $\mathrm{K}_{0}$ and $\delta_{\mathrm{M}}$ were free variables in the fitting while $\delta_{\mathrm{L}}$ was measured in the ligand solution before the addition of $\mathrm{MCl}_{2}$. Datapoints were not plotted or included in fitting where the measured $\left[\mathrm{M}^{2+}\right]_{\mathrm{f}}$ exceeded the maximum value obtained in the calibration experiments $\left(88 \mathrm{mM}\right.$ and $100 \mathrm{mM}$ for $\mathrm{Ca}^{2+}$ and $\mathrm{Mg}^{2+}$ respectively).

Molecular dynamics. The input co-ordinates for the $\mathrm{M}^{2+}$ ion and malate for the MD simulations were generated by loading four units of a calcium malate ${ }^{38}$ into Schrödinger Maestro ${ }^{39}$ and selecting a $\mathrm{g}^{-}$malate calcium pair for exporting as separate .pdb files. The .pdb co-ordinate file for malate and calcium was converted into .mol2 for the simulation using antechamber from the amber toolkit. ${ }^{40}$ The co-ordinates for the calcium ion were used to produce a .mol2 file for the magnesium ion. Parameters for malate were generated using GAFF and parameters for the calcium and magnesium cations were taken from the parm 10 force field. ${ }^{41}$

Three systems were built in total, $\mathrm{Mg}^{2+}$ - Malate, $\mathrm{Ca}^{2+}$ - Malate and Malate alone. Molecular dynamics simulations for the systems were ran with the Amber PMEMD software. ${ }^{41}$ Each of the three systems was solvated using TIP3P water in a truncated icosahedral box with a minimum buffer of $10 \AA$. Once built, each system was then minimised under a constraint of 20 kcal $\mathrm{mol}^{-1} \AA^{-2}$ on solute atoms and then minimised again without constraints. Each system was then heated to $300 \mathrm{~K}$ and then raised to a pressure of 1 atm in two steps both 500 ps respectively. In both heating and pressure steps constraints of $20 \mathrm{kcal} \mathrm{mol}^{-1} \AA^{-2}$ were used on solute atoms. Restraints were then released to $0 \mathrm{kcal} \mathrm{mol}^{-1} \AA^{-2}$ in four $500 \mathrm{ps}$ steps, reducing the constraints by $5 \mathrm{kcal} \mathrm{mol}^{-1} \AA^{-2}$ each step. The systems were then simulated for $10 \mathrm{~ns}$ using a 1 fs time step, sampling frames every $2.5 \mathrm{ps}$. Bond lengths involving hydrogens were constrained using the SHAKE algorithm. The pressure was kept constant using a Berendsen barostat and for temperature control, a Langevin thermostat with a $5 \mathrm{ps}^{-1}$ collision frequency was used. The non-bonded atom cutoff was set to $8 \AA$.

\section{RESULTS AND DISCUSSION}

A method for the determination of $\left[\mathrm{M}^{2+}\right]$ by ${ }^{1} \mathrm{H}$ NMR. To be effective as an $\mathrm{M}^{2+}$ indicator $\left(\mathrm{M}=\mathrm{Ca}^{2+}\right.$ or $\mathrm{Mg}^{2+}$ in this work), a ligand should possess an $\mathrm{M}^{2+}$ binding constant comparable with the concentration range of interest. Many small mono- and dicarboxylate ligands possess binding constants of between 10 and $300 \mathrm{M}^{-1} .27$ This matches well with the concentration range of $1-100 \mathrm{mM}$ which is of interest for a range of systems including soft-materials ${ }^{12,23,42}$ small molecule metabolites $^{6,43}$ and some proteins. ${ }^{44}$ These ligands exhibit a rapid exchange on the NMR timescale between their free and complexed states ${ }^{29}$ The observed chemical shift, $\delta$, of an indicator ligand is therefore given by: ${ }^{17,20}$

$\delta=\frac{\left[\mathrm{M}^{2+}\right]_{\mathrm{f}} \mathrm{K}_{\mathrm{M}} \delta_{\mathrm{M}}+\delta_{\mathrm{L}}}{1+\left[\mathrm{M}^{2+}\right]_{\mathrm{f}} \mathrm{K}_{\mathrm{M}}}$ where $\delta_{\mathrm{M}}$ and $\delta_{\mathrm{L}}$ are the limiting chemical shifts of the fully complexed and free ligands respectively and $\left[\mathrm{M}^{2+}\right]_{\mathrm{f}}$ is the free concentration of divalent metal ions. $\mathrm{K}_{M}$ is the complexation constant of a ligand of negative charge, $n$, given by:

$\mathrm{K}_{\mathrm{M}}=\frac{\left[\mathrm{ML}^{2-\mathrm{n}}\right]}{\left[\mathrm{M}^{2+}\right]_{\mathrm{f}}\left[\mathrm{L}^{-\mathrm{n}}\right]}$

Provided $\mathrm{K}_{\mathrm{M}}, \delta_{\mathrm{M}}$ and $\delta_{\mathrm{L}}$ are known, $\left[\mathrm{M}^{2+}\right]_{\mathrm{f}}$ may be calculated from Equation 3:

$\left[\mathrm{M}^{2+}\right]_{\mathrm{f}}=\frac{\left(\delta_{\mathrm{L}}-\delta\right)}{\mathrm{K}_{\mathrm{M}}\left(\delta-\delta_{\mathrm{M}}\right)}$

$\mathrm{K}_{\mathrm{M}}$ is related to the thermodynamic binding constant, $\mathrm{K}_{0}$, by the equation:

$\mathrm{K}_{0}=\frac{\gamma_{\mathrm{ML}^{2-\mathrm{n}}\left[\mathrm{ML}^{2-\mathrm{n}}\right]}}{\gamma_{\mathrm{M}^{2+}} \gamma_{\mathrm{L}^{-n}}\left[\mathrm{M}^{2+}\right]_{\mathrm{f}}\left[\mathrm{L}^{-\mathrm{n}}\right]}$

where $\gamma$ represents the activity coefficients of the different species. If the approximation is made that the activity coefficient of a species depends solely on the magnitude of its charge ${ }^{45-47}$ then $\mathrm{K}_{\mathrm{M}}$ and $\mathrm{K}_{0}$ may be interconverted using the relation:

$\mathrm{K}_{\mathrm{M}}=\gamma_{2} \mathrm{~K}_{0}$

for a ligand with $n=1 . \gamma_{2}$ is the activity coefficient of a divalent ion. For a ligand with $\mathrm{n}=2$ :

$\mathrm{K}_{\mathrm{M}}=\gamma_{2}^{2} \mathrm{~K}_{0}$

$\gamma_{2}$ may be calculated using the Davies equation:47-49

$\log _{10}\left(\gamma_{2}\right)=-2.04\left(\frac{\sqrt{\mathrm{I}}}{1+\sqrt{\mathrm{I}}}-0.3 \mathrm{I}\right)$

where I is the ionic strength of the solution. All ionic strengths in this work are calculated in terms of molarity rather than molality as the difference between the two scales introduces negligible error into our calculations.

An extensive screening of indicator ligands was performed and a working set assembled. Details of all ligands tested are provided in Section S-6 in the Supporting Information. Glycolate and sulfoacetate were selected as the principal indicators in this study owing to their sensitive chemical shifts and low $\mathrm{p} K_{\mathrm{a}}$ values $(\leq 4)$ permitting their use at $\mathrm{pH} \geq 7$ (Section $\mathrm{S}$ 7). ${ }^{25,50}$ The chemical shifts of glycolate and SFA are invariant between $\mathrm{pH} 7$ and $\mathrm{pH} 12$ when DSS, DMSO or methanol are used as chemical shift references (Figure S-7, c). In contrast, we note that nucleotide-based ${ }^{31} \mathrm{P}$ indicators are $\mathrm{pH}$ sensitive above $\mathrm{pH} 7$ due to the high $\mathrm{p} K_{\mathrm{a}}$ value of the terminal phosphate group and require careful recalibration at each $\mathrm{pH}^{20,21}$ The performance of glycolate and SFA is not affected by their concentration or by the presence of the $\mathrm{pH}$ indicator compounds (Section S-7). Methanedisulfonate (KDS) may be used at acidic $\mathrm{pH}$ but requires recalibration for different background ionic media (Section S-6 and Figure S-8). The chemical shifts of glycolate and SFA are plotted as a function of $\left[\mathrm{M}^{2+}\right]_{\mathrm{f}}$ on Figure $1 .\left[\mathrm{M}^{2+}\right]_{\mathrm{f}}$ was calculated as described in the Experimental section for the calibration of the indicator ligands. Spectra are provided in Section S-8. 


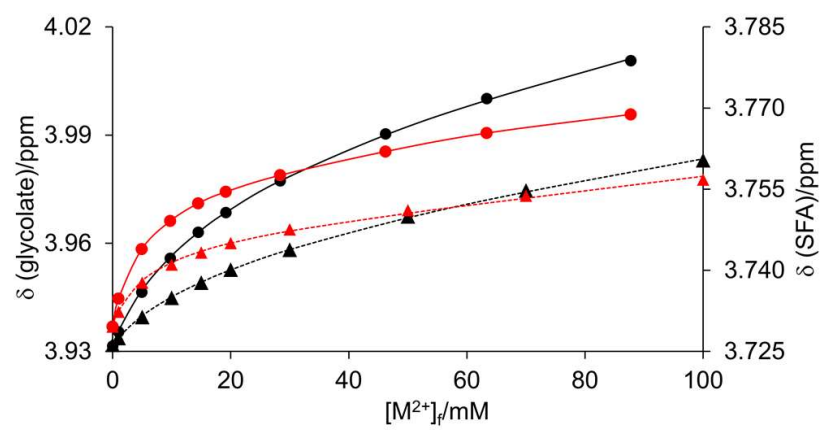

Figure 1. Plot of observed chemical shift of glycolate (black) and SFA (red) versus free concentrations of $\mathrm{Ca}^{2+}$ (circle) and $\mathrm{Mg}^{2+}$ (triangle). The lines are fits to Equation 1.

The data of Figure 1 was fitted to Equation 1 with $\mathrm{K}_{\mathrm{M}}$ corrected for ionic strength at each point of the titration using Equations 5, 6 and 7. $\delta_{\mathrm{M}}$ and $\mathrm{K}_{0}$ were treated as free parameters in the fitting (Table 1). $\delta_{\mathrm{L}}$ was measured in the absence of $\mathrm{M}^{2+}$. The $\mathrm{K}_{0}$ values of glycolate are in excellent agreement with the literature values of $30.2-38.9 \mathrm{M}^{-1}$ for $\mathrm{Ca}^{2+}$ and 19.5-21.4 $\mathrm{M}^{-1}$ for $\mathrm{Mg}^{2+} \cdot{ }^{27}$ Reliable literature values for SFA could not be found.

Table 1. $K_{0}, \delta_{L}$ and $\delta_{M}$ values of glycolate and SFA

\begin{tabular}{|l|l|l|l|l|l|}
\hline Ligand & $\mathbf{K}_{\mathbf{0}, \mathrm{Ca}} / \mathbf{M}^{-1}$ & $\mathbf{K}_{\mathbf{0}, \mathbf{M g}} / \mathbf{M}^{-1}$ & $\delta_{\mathbf{L}} / \mathbf{p p m}^{*}$ & $\delta_{\mathrm{Ca}} / \mathbf{p p m}$ & $\delta_{\mathbf{M g}} / \mathbf{p p m}$ \\
\hline Glycolate & 31.3 & 21.1 & 3.9317 & 4.1123 & 4.0669 \\
& \pm 0.5 & \pm 0.5 & \pm 0.0002 & \pm 0.0023 & \pm 0.0028 \\
& & & & & \\
\hline SFA & 105.1 & 71.5 & 3.7296 & 3.8215 & 3.8043 \\
& \pm 3.1 & \pm 2.4 & \pm 0.0002 & \pm 0.0020 & \pm 0.0009 \\
\hline
\end{tabular}

Values are quoted as the average of two titrations \pm half the difference. *Average of eight samples.

Automatic ionic background compensation. In order to calculate $\left[\mathrm{M}^{2}\right]_{\mathrm{f}}$ from Equation 3, it is necessary to know the ionic strength of the solution. However, the calculation of the ionic strength requires that the identity, concentration, complexation state and protonation state of all species be known. ${ }^{48,51-53}$ In many systems, the ionic strength is either unknown or inconvenient to compute. Furthermore, other cations can compete with $\mathrm{M}^{2+}$ for the indicator ligands causing additional changes to the apparent $\mathrm{K}_{\mathrm{M}}$ beyond ionic strength effects. Nevertheless, we shall show how by using glycolate (n $=1)$ and SFA $(n=2)$ together it is possible to automatically compensate for these effects. Both ligands in the sample are necessarily at the same $\left[\mathrm{M}^{2+}\right]_{\mathrm{f}}$ and ionic strength. By combining Equations 3, 5 and 6 we may write:

$\gamma_{2}=\frac{\mathrm{K}_{1}\left(\delta_{\mathrm{L} 2}-\delta_{2}\right)\left(\delta_{1}-\delta_{\mathrm{M} 1}\right)}{\mathrm{K}_{2}\left(\delta_{2}-\delta_{\mathrm{M} 2}\right)\left(\delta_{\mathrm{L} 1}-\delta_{1}\right)}$

where the subscripts denote the charges of the ligands and $\mathrm{K}$ the thermodynamic binding constants. We may thus obtain $\gamma_{2}$ and $\left[\mathrm{M}^{2+}\right]_{\mathrm{f}}$ without knowledge of the ionic composition of the sample, provided the indicator ligands are not affected by cations other than $\mathrm{M}^{2+}$. To test the sensitivity of the ligands to other cations, samples were prepared as for the calibration experiments but with constant concentrations of different univalent salts in addition to the $\mathrm{MCl}_{2}$ (Figures 2 and $\mathrm{S}-13$ ). The chemical shifts of the indicator ligands are dependent on the identity of the background salt and cannot be predicted adequately by correcting $\mathrm{K}_{\mathrm{M}}$ for the ionic strength. The chemical shift of SFA is affected to a greater extent than glycolate due to its higher charge and greater affinity for monovalent ions. ${ }^{27}$
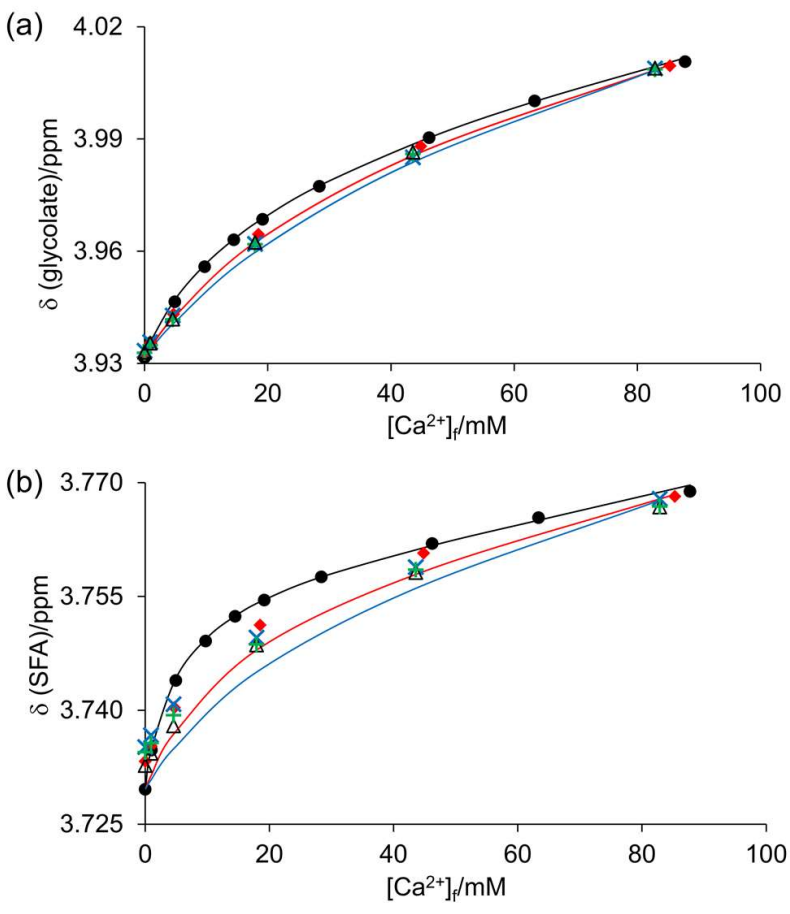

Figure 2. Plot of observed chemical shifts of glycolate (a) and SFA (b) as function of free $\mathrm{Ca}^{2+}$ concentration in different ionic media: none (black circle), $50 \mathrm{mM} \mathrm{NaCl}$ (red diamond), $100 \mathrm{mM} \mathrm{NaCl}$ (blue cross), $100 \mathrm{mM} \mathrm{KCl}$ (green cross) and $100 \mathrm{mM} \mathrm{MeNH}_{3} \mathrm{Cl}+2 \mathrm{mM} \mathrm{NaOH}$ (white triangle). Lines are chemical shifts predicted using parameters in Table 1 and Equations 1 and 7: none (black), $50 \mathrm{mM} \mathrm{I}$ (red) and $100 \mathrm{mM} \mathrm{I}$ (blue).

To further correct for the ionic background, we may make the approximation that the background cations behave as though they were an effective concentration of $\mathrm{M}^{2+}$. As glycolate and SFA will interact with the background cations to different extents, this effective $\left[\mathrm{M}^{2+}\right]$ will be different for each ligand. However, upon addition of $\mathrm{M}^{2+}$ to a sample, the change in $\left[\mathrm{M}^{2+}\right]_{\mathrm{f}}$ will necessarily be the same for each ligand and will be equal to the true $\left[\mathrm{M}^{2+}\right]_{\mathrm{f}}$. Modifying Equation 3, we may obtain $\left[\mathrm{M}^{2+}\right]_{\mathrm{f}}$ as:

$\left[\mathrm{M}^{2+}\right]_{\mathrm{f}}=\frac{\left(\delta_{\mathrm{L} 1}-\delta_{\mathrm{M} 1}\right)\left(\delta_{\mathrm{a} 1}-\delta_{\mathrm{b} 1}\right)}{\mathrm{K}_{1} \gamma_{2}\left(\delta_{\mathrm{b} 1}-\delta_{\mathrm{M} 1}\right)\left(\delta_{\mathrm{a} 1}-\delta_{\mathrm{M} 1}\right)}$

where $\delta_{\mathrm{a}}$ is the ligand chemical shift measured in the background medium in the absence of $\mathrm{M}^{2+}$ and $\delta_{\mathrm{b}}$ is the shift measured in the solution under study. Similarly, $\gamma_{2}$ may be obtained from Equation 8 as:

$\gamma_{2}=\frac{\mathrm{K}_{1}\left(\delta_{\mathrm{L} 2}-\delta_{\mathrm{M} 2}\right)\left(\delta_{\mathrm{a} 2}-\delta_{\mathrm{b} 2}\right)\left(\delta_{\mathrm{a} 1}-\delta_{\mathrm{M} 1}\right)\left(\delta_{\mathrm{b} 1}-\delta_{\mathrm{M} 1}\right)}{\mathrm{K}_{2}\left(\delta_{\mathrm{b} 2}-\delta_{\mathrm{M} 2}\right)\left(\delta_{\mathrm{a} 2}-\delta_{\mathrm{M} 2}\right)\left(\delta_{\mathrm{L} 1}-\delta_{\mathrm{M} 1}\right)\left(\delta_{\mathrm{a} 1}-\delta_{\mathrm{b} 1}\right)}$

Equations 9 and 10 allow $\left[\mathrm{M}^{2+}\right]_{\mathrm{f}}$ to be recovered with good accuracy in different background ionic media (Figure 3). $\left[\mathrm{M}^{2+}\right]_{\mathrm{f}}$ was calculated as described in the Experimental Section. Using Equations 3 and 8 directly in these ionic media results in large errors in $\left[\mathrm{M}^{2+}\right]_{\mathrm{f}}$ and unacceptable values of $\gamma_{2}$, 
particularly at lower $\mathrm{M}^{2+}$ concentrations (Figure S-14). The use of Equations 9 and 10 is thus necessary when significant concentrations of background cations are present.
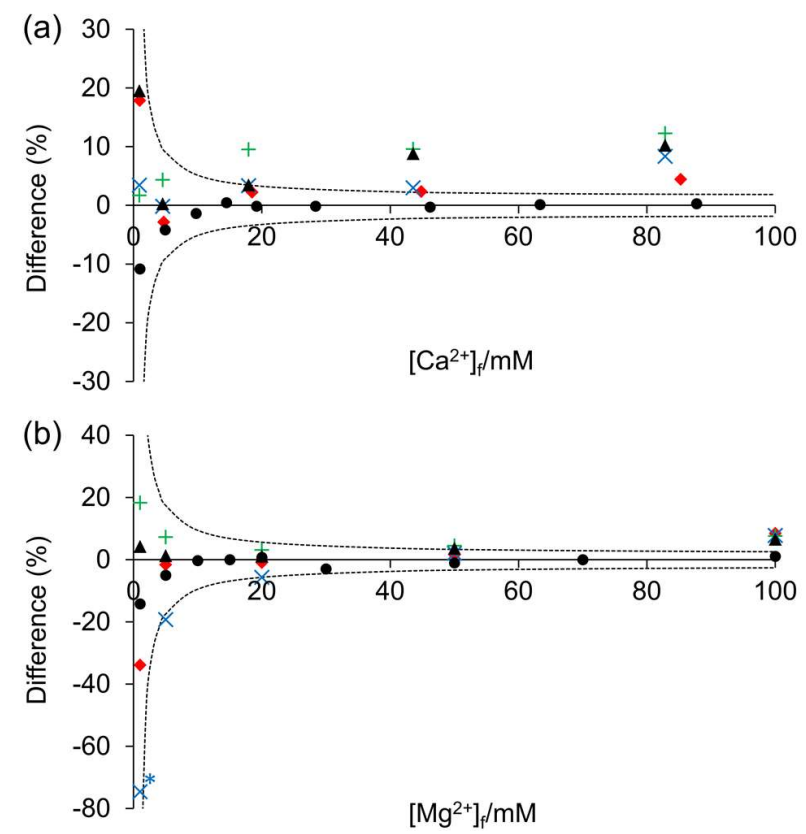

Figure 3. Error $\left(\left[\mathrm{M}^{2+}\right]_{\mathrm{NMR}}-\left[\mathrm{M}^{2+}\right]_{\text {calculated }}\right) /\left[\mathrm{M}^{2+}\right]_{\text {calculated }}$ in $\left[\mathrm{Ca}^{2+}\right]_{\mathrm{f}}$ (a) and $\left[\mathrm{Mg}^{2+}\right]_{\mathrm{f}}$ (b) obtained by NMR in different ionic media using Equations 9 and 10: none (black circle), $50 \mathrm{mM} \mathrm{NaCl}$ (red diamond), $100 \mathrm{mM} \mathrm{NaCl}$ (blue cross), $100 \mathrm{mM} \mathrm{KCl}$ (green cross) and $100 \mathrm{mM} \mathrm{MeNH} \mathrm{H}_{3} \mathrm{Cl}+2 \mathrm{mM} \mathrm{NaOH}$ (black triangle). The maximum errors arising from a $\pm 0.1 \mathrm{~Hz}$ uncertainty in the chemical shifts are plotted as dashed lines. The point marked * may be identified as unreliable from the reported value of $\gamma_{2}$.

The uncertainty in the measurement of a line position can be taken as $0.1 \mathrm{~Hz}\left(\delta_{\mathrm{L}}\right.$, Table 1$)$ which imposes a fundamental limitation on the accuracy of our method. Due to the dependence of the ligand chemical shifts on $\left[\mathrm{M}^{2+}\right]_{\mathrm{f}}$ (Figure 1), the error in the measured $\left[\mathrm{M}^{2+}\right]_{\mathrm{f}}$ is strongly dependent upon the actual $\left[\mathrm{M}^{2+}\right]_{\mathrm{f}}$. This error, expressed as a percentage, is plotted on Figure 3. To compute this error, the chemical shifts of glycolate and SFA were calculated using Equations 1, 5, 6 and 7 with a background ionic strength of $0.1 \mathrm{M}$. The shifts were modified by $\pm 0.1 \mathrm{~Hz}$ and $\left[\mathrm{M}^{2+}\right]_{\mathrm{f}}$ recalculated using Equations 3 and 8 . The combination of errors in the shifts which gave the largest error in $\left[\mathrm{M}^{2+}\right]_{\mathrm{f}}$ was chosen and this error plotted. This error becomes significant only at $\mathrm{M}^{2+}$ concentrations below 5 $\mathrm{mM}$. Plots of the error in $\left[\mathrm{M}^{2+}\right]_{\mathrm{f}}$ as a function of the uncertainty in the chemical shifts of both indicators are provided on Figure S-15. The value of $\gamma_{2}$ obtained from Equation 10 may be used to check the reliability of the $\left[\mathrm{M}^{2+}\right]_{\mathrm{f}}$ measurements obtained, provided some prior knowledge of the ionic composition of the sample exists. For the simple non-complexing electrolytes of Figure 3, the ionic strength may be calculated from the reported $\left[\mathrm{M}^{2+}\right]_{\mathrm{f}}$ using Equation 11:

$\mathrm{I}=\mathrm{I}_{0}+3\left[\mathrm{M}^{2+}\right]_{\mathrm{f}}$

where $\mathrm{I}_{0}$ is the ionic strength in the absence of added $\mathrm{M}^{2+}$. Complexation of $\mathrm{M}^{2+}$ by the electrolyte requires modification of the $\mathrm{I}_{0}$ term (Equation S-14). Maximum/minimum permissible values of $\gamma_{2}$ may be computed from Equations 7 and 11, based on an acceptable percentage tolerance, $\pm \mathrm{h}$, in the reported $\left[\mathrm{M}^{2+}\right]_{\mathrm{f}}$ (Equation 12):

$\gamma_{2, \max / \min }=\frac{\gamma_{(\mathrm{I})}}{1 \pm \mathrm{h} / 100}$

With the exception of one data point at $1 \mathrm{mM} \mathrm{Mg}^{2+}, 100 \mathrm{mM}$ $\mathrm{NaCl}$, all points on Figure 3 return acceptable $\gamma_{2}$ values with $\mathrm{h}$ $=20 \%$ and the reported $\left[\mathrm{M}^{2+}\right]_{\mathrm{f}}$ are reliable to $20 \%$. Extracted $\gamma_{2}$ values are provided on Figure S-14, c. We note that there is an inherent uncertainty in the calculation of $\gamma_{2}$ from Equations 7 and 11, particularly at higher ionic strengths. ${ }^{48,54}$ More accurate calculations of $\gamma_{2}$ require the specific properties of the sample components to be taken into account which is not feasible for many systems of interest. Reducing h to $10 \%$ results in the significant rejection of points that return acceptable $\left[\mathrm{M}^{2+}\right]_{\mathrm{f}}$ values (Figure $\mathrm{S}-12$ ). We note that $\mathrm{h}$ can be adjusted to gauge the reliability of the reported $\left[\mathrm{M}^{2+}\right]_{\mathrm{f}}$ (Figure $\left.\mathrm{S}-7, \mathrm{~b}\right)$. To further test the method, we note that $\left[\mathrm{Ca}^{2+}\right]_{\mathrm{f}}$ can be determined in the presence of $10 \mathrm{mM} \mathrm{MgCl} 2$ but $\left[\mathrm{Mg}^{2+}\right]_{\mathrm{f}}$ cannot be determined in the presence of $10 \mathrm{mM} \mathrm{CaCl}_{2}$ as unphysical values of $\gamma_{2}$ are returned that are rejected by Equations 11 and 12 (Figure $\mathrm{S} 11, \mathrm{c}, \mathrm{d})$.

We note that it is theoretically possible for an interferent cation to give highly erroneous values of $\left[\mathrm{M}^{2+}\right]_{\mathrm{f}}$ but acceptable values of $\gamma_{2}$ from Equation 10 (Section S-9, Figure S11, e). However, this behavior is not observed for any of the cations tested in this work. When different background cations are present, it is recommended to test the indicator ligands in samples of known $\left[\mathrm{M}^{2+}\right]_{\mathrm{f}}$ in the absence of strongly complexing background anions. The indicator ligands are not affected by the identity of the background anions present (Tables S-6 and S-7).

$\left[\mathrm{M}^{2+}\right]_{\mathrm{f}}$ determinations in the presence of a complexing ligand. $\mathrm{M}^{2+}$ ions bound to a complexing ligand or macromolecule are, by definition (Equations 2 and 3), not available in solution to bind to the indicator ligands. The M-ligand complex may nevertheless be able to interact with the indicator ligands to some extent. To test the physical meaning of the reported $\left[\mathrm{M}^{2+}\right]_{\mathrm{f}}$ values in the presence of a complexing ligand, titrations were performed with $50 \mathrm{mM}$ disodium maleate as a background electrolyte. Maleate was chosen for this part of the study due to the high solubility of its calcium and magnesium complexes as well as its relatively high binding constants. ${ }^{55}$ The measured $\left[\mathrm{M}^{2+}\right]_{\mathrm{f}}$ is plotted on Figure 4 along with the theoretical concentration.

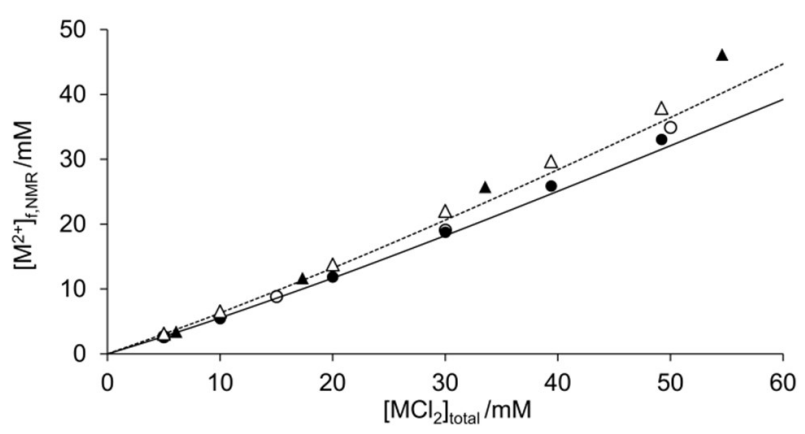

Figure 4. Plot of $\left[\mathrm{Mg}^{2+}\right]_{\mathrm{f}}$ (triangle) and $\left[\mathrm{Ca}^{2+}\right]_{\mathrm{f}}$ (circle) obtained by NMR versus total $\mathrm{M}^{2+}$ in $50 \mathrm{mM}$ disodium maleate. Replicate titrations are shown with hollow and solid symbols. The theoretical $\left[\mathrm{M}^{2+}\right]_{\mathrm{f}}$ is plotted as dashed $\left(\mathrm{Mg}^{2+}\right)$ and solid $\left(\mathrm{Ca}^{2+}\right)$ lines. 
The theoretical $\left[\mathrm{M}^{2+}\right]_{\mathrm{f}}$ was obtained using an iterative procedure described in Section S-12, using the $\log \left(\mathrm{K}_{0}\right)$ values for maleate provided in Table 2 (vide infra). The measured $\left[\mathrm{M}^{2+}\right]_{\mathrm{f}}$ is within $10 \%$ of the theoretical value across all points, confirming that glycolate and SFA can distinguish between free $\mathrm{M}^{2+}$ ions in solution and $\mathrm{M}^{2+}$ bound to complexing ligands such as maleate. The value of $\gamma_{2}$ obtained from Equation 10 is in excellent agreement with the simulated value (Figure S-16). It is not possible to calculate $\gamma_{2}$ from Equation 7 without prior knowledge of the maleate binding constant as well as the total concentration of $\mathrm{M}^{2+}$ in the sample. Equation 10 is thus vital when studying novel samples for which binding data is not available. Equations 9 and 10 also allow the measurement of $\left[\mathrm{M}^{2+}\right]_{\mathrm{f}}$ by chemical shift imaging along $\mathrm{M}^{2+}$ gradients where the total concentration of $\mathrm{M}^{2+}$ in a voxel is unknown.

Directly fitting the data on Figure 4, utilizing the experimentally determined values of $\gamma_{2}$, returns $\log \left(\mathrm{K}_{0}\right)$ values of 2.3 and 2.1 for $\mathrm{Ca}$ and $\mathrm{Mg}$ respectively (Figure $\mathrm{S}-17$ ) in good agreement with literature data (Table 2).

Ligand binding analysis using NMR Imaging. A common approach to understand the $\mathrm{M}^{2+}$ binding properties of organic ligands is to acquire series of NMR spectra of the ligand as a function of the $\mathrm{M}^{2+}$ concentration. ${ }^{29,43,56,57}$ In the conventional procedure, each spectrum is recorded separately and the $\mathrm{M}^{2+}$ concentration adjusted manually between successive NMR experiments. The free $\mathrm{M}^{2+}$ concentration can be measured electrochemically ${ }^{6,58}$ or, depending upon the required accuracy, simply assumed equal to the total concentration of $\mathrm{M}^{2+}$ salt added. ${ }^{43}$ A more efficient procedure is to instead establish an $\mathrm{M}^{2+}$ concentration gradient in a standard NMR tube and collect the required series of spectra as a function of the free $\mathrm{M}^{2+}$ concentration along the length of the sample using chemical shift imaging techniques. ${ }^{25}$ The self-correcting methodology described in this work can be readily applied using imaging techniques. No background electrolyte is required for the NMR measurements, permitting the study of the ligands at high dilution in the absence of competitive counterions.

Five low molecular weight carboxylic acid ligands were selected for this work: ${ }_{\mathrm{L}}$-lactate, maleate, malonate, ${ }_{\mathrm{L}}$-tartrate and 1,2,4,5-benzenetetracarboxylate (pyromellitate). These ligands have been well-studied and high quality binding data is available by which the NMR imaging method may be validated. ${ }^{27,59}$ $\mathrm{M}^{2+}$ gradients were established in $5 \mathrm{~mm}$ sample tubes and the ligand chemical shifts extracted from the images (Section S13). The ligand chemical shifts were thus obtained as a function of $\left[\mathrm{M}^{2+}\right]_{\mathrm{f}}$ and binding constants obtained by fitting the data to Equations 1, 5 (L-lactate) and 6. Example fits are provided on Figure S-20. Fitted binding constants are provided in Table 2.

Table 2. $\log \left(\mathrm{K}_{0}\right)$ values of ligands obtained using imaging.

\begin{tabular}{|l|l|l|l|l|}
\hline Ligand & $\log \left(\mathbf{K}_{\mathbf{0}, \mathbf{C a})}\right.$ & $\begin{array}{l}\log \left(\mathbf{K}_{\mathbf{0}, \mathbf{C a}}\right), \\
\text { Lit. }^{27}\end{array}$ & $\log \left(\mathbf{K}_{\mathbf{0}, \mathbf{M g})}\right.$ & $\begin{array}{l}\mathbf{L o g}\left(\mathbf{K}_{\mathbf{0}, \mathbf{M g}}\right), \\
\text { Lit. }^{27}\end{array}$ \\
\hline L-lactate & $1.39 \pm 0.01$ & $1.42-1.47$ & $1.32 \pm 0.02$ & $1.30-1.35$ \\
\hline maleate & $2.32 \pm 0.02$ & 2.40 & $2.20 \pm 0.01$ & 2.30 \\
\hline malonate & $2.27 \pm 0.05$ & $2.35-2.50$ & $2.83 \pm 0.01$ & $2.86-2.92$ \\
\hline L-tartrate & $2.68 \pm 0.01$ & $2.89-2.98$ & $2.08 \pm 0.03$ & 2.35 \\
\hline
\end{tabular}

Values are quoted as the average of three titrations \pm the standard deviation.

Good agreement is obtained between NMR and the literature values. The slight discrepancies are attributable to the inherent approximations in Equations 1, 5, 6 and 7; we note that $\delta$ is likely to depend slightly upon the ionic strength of the solution

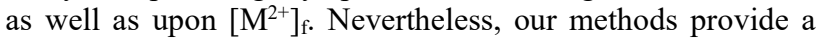
simple and efficient way to assess the binding strength of a ligand, if only a semi-quantitative analysis is required. Pyromellitate $\left(\mathrm{P}^{4-}\right)$ is capable of associating with two $\mathrm{M}^{2+}$ ions ${ }^{59}$ and Equation 1 must be modified to incorporate an additional binding step (Equation S-15). The high stability of the $\mathrm{P}^{4-} \mathrm{M}^{2+}$ complex $\log \left(\mathrm{K}_{0}\right)>3.5$ is outside the range of our indicators. Nevertheless, the second binding step may be characterized with reasonable accuracy and our method may be used to study, at least qualitatively, the binding of such strong ligands (Figures S-21 and S-22).

Conformational analysis of a ligand as a function of $\left[\mathrm{M}^{2+}\right]$. The conformation of a ligand determines its chemical and biological activity. NMR spectroscopy is an extremely powerful technique to probe conformational distributions of ligands. ${ }^{56,60-62}$ With our method, the measured $\left[\mathrm{M}^{2}\right]_{\mathrm{f}}$ is automatically corrected for both ionic strength and complexation, allowing a high concentration of ligand to be used for optimum sensitivity. Using an internal $\mathrm{M}^{2+}$ gradient and imaging techniques, it is possible to attain the conformational distribution of a ligand as a function of $\left[\mathrm{M}^{2+}\right]_{\mathrm{f}}$ with a high number of datapoints. We can thus gain insight into the binding modes of the ligand to $\mathrm{M}^{2+}$.

Malate was chosen as a model ligand for this part of the study. The conformational distribution of malate may be deduced from the magnitudes of the ${ }^{3} \mathrm{~J}_{\mathrm{AX}}$ and ${ }^{3} \mathrm{~J}_{\mathrm{BX}}$ couplings as discussed by Stouten et al. ${ }^{62}$ Briefly, due to rapid exchange on the NMR time scale, the observed coupling, $J_{\mathrm{obs}}$, is a population weighted average of the specific couplings of each conformer (Equation 13):

$\mathrm{J}_{\mathrm{obs}}=\mathrm{f}_{\mathrm{g}^{-}} \mathrm{J}_{\mathrm{g}^{-}}+\mathrm{f}_{\mathrm{t}} \mathrm{J}_{\mathrm{t}}+\mathrm{f}_{\mathrm{g}^{+}} \mathrm{J}_{\mathrm{g}^{+}}$

where $f$ denotes the fraction of ligand in each conformer and $f_{g-}+f_{t}+f_{g+}=1$. The subscripts denote the conformers on Figure $5 \mathrm{a}$. The specific couplings of each conformer may be calculated as described in Reference 62 and are taken from Table 4 of this reference. We assume that the specific couplings of each conformer are not affected significantly by complexation to $\mathrm{M}^{2+}$.

$\mathrm{M}^{2+}$ gradients were established in $5 \mathrm{~mm}$ NMR tubes and ${ }^{3} \mathrm{~J}_{\mathrm{AX}}$ and ${ }^{3} J_{\mathrm{BX}}$ extracted as a function of $\left[\mathrm{M}^{2+}\right]_{\mathrm{f}}$ from the NMR images. These couplings were fitted simultaneously to Equation 13 in order to determine the conformer distributions. Spectra are provided on Figure S-23. The distribution of conformers as a function of $\left[\mathrm{M}^{2+}\right]_{\mathrm{f}}$ is plotted on Figure $5 \mathrm{~b}$.

In common with other works, trans $(\mathrm{t})$ is observed to be the dominant conformer of the malate dianion. ${ }^{62}$ Upon addition of $\mathrm{M}^{2+}$, the populations of the $\mathrm{g}^{+}$and $\mathrm{g}^{-}$conformers increase as the population of the trans conformer decreases. Fitting the combined chemical shifts of malate to Equation 1 and 6 returns $\log \left(\mathrm{K}_{0}\right)$ values of 2.55 and 2.43 for $\mathrm{Ca}$ and $\mathrm{Mg}$ respectively (Figure S-24) which are in reasonable agreement with literature values of 2.55-2.77 and 2.30. ${ }^{27}$ Based on the measured binding constants and $\gamma_{2}$ values, the fraction of malate bound to $\mathrm{M}^{2+}$ may be calculated using Equation 2. A gauche conformation may be expected to favour coordination as the carboxylate groups are on the same side of the malate anion. However, above $5 \mathrm{mM}\left[\mathrm{M}^{2+}\right]$, the fraction of malate in the gauche conformations is less than the total fraction of bound malate. This observation implies that the trans conformer is also capable of coordinating to $\mathrm{M}^{2+}$. 
(a)

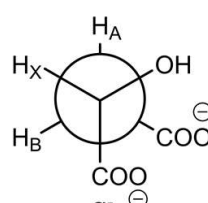

(b)

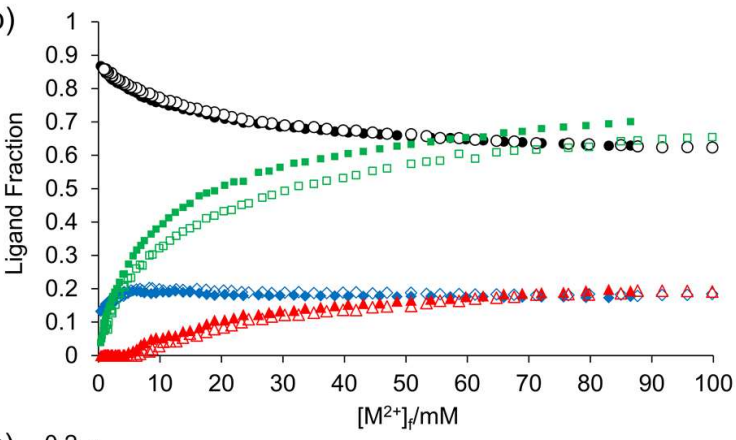

(c)

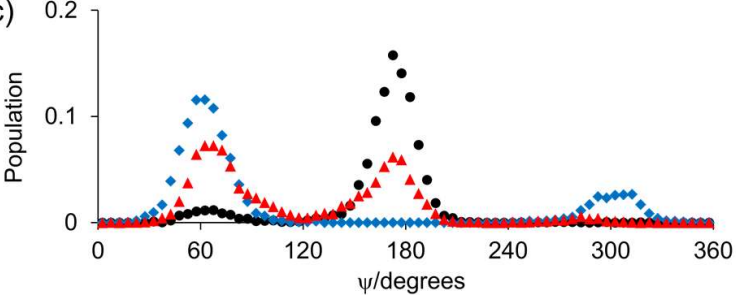

Figure 5. (a) Newman projections of the three staggered con-

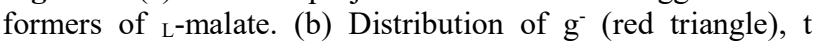
(black circle) and $\mathrm{g}^{+}$(blue diamond) conformers determined by NMR as function of $\left[\mathrm{Ca}^{2+}\right]_{\mathrm{f}}$ (solid) and $\left[\mathrm{Mg}^{2+}\right]_{\mathrm{f}}$ (hollow). Fraction of malate bound to $\mathrm{M}^{2+}$ (green square). The concentration of ligands in this sample was $10 \mathrm{mM}$ DL-malate, $1 \mathrm{mM}$ glycolate and $1 \mathrm{mM} \mathrm{SFA}$. (c) Angular distribution of malate in presence of $\mathrm{Ca}^{2+}$ (blue diamond), $\mathrm{Mg}^{2+}$ (red triangle) and absence of $\mathrm{M}^{2+}$ (black) obtained by molecular dynamics simulations.

To gain further insight into the binding modes of malate, we performed molecular dynamics (MD) simulations in the presence and absence of $\mathrm{M}^{2+}$. The dihedral angle ( $\psi$, Figure 5a) of malate was obtained as a function of time and histograms created (Figure 5, c). In agreement with the NMR, trans was observed to be the dominant conformer in the absence of $\mathrm{M}^{2+}$ with minor amounts of $\mathrm{g}^{+}$present. Upon inclusion of a $\mathrm{Ca}^{2+}$ ion, the malate remained associated with the ion and flipped between the $\mathrm{g}^{+}$(major) and $\mathrm{g}^{-}$(minor) conformers. Upon inclusion of a $\mathrm{Mg}^{2+}$ ion, $\mathrm{g}^{+}$was again observed to be the dominant conformation. However, a monodentate coordination mode involving only one of the carboxylates was observed with the malate in a trans conformation (Figure S-25). As our simulations cannot be expected to quantitatively reproduce the binding constants or the experimental conditions of the NMR, we infer that a similar coordination mode is possible to $\mathrm{Ca}^{2+}$. In common with other flexible ligands, several 'bound' states of malate exist in equilibrium which interconvert rapidly on the NMR timescale. ${ }^{56,60}$ Using the methodology presented in this work, we have obtained full titration curves and conformer distributions in single 37 minute NMR imaging experiments.

\section{SUMMARY OF METHOD}

To measure the free $\mathrm{Ca}^{2+}$ or $\mathrm{Mg}^{2+}$ concentration in a sample at pH 7-12, sodium glycolate and sodium sulfoacetate (SFA) are included along with a suitable internal chemical shift reference: DSS, methanol or DMSO. These compounds can be included at any concentration; however, it should be noted that complexation of $\mathrm{M}^{2+}$ by the ligands will occur. Ligand concentrations of 0.05 to $10 \mathrm{mM}$ were tested in this work. To correct for the background medium, the chemical shifts of glycolate and SFA are measured both in the sample of interest and in an analogous sample that does not contain $\mathrm{M}^{2+}$. The free $\mathrm{M}^{2+}$ concentration and $\gamma_{2}$ may be obtained from Equations 9 and 10. From the reported $\mathrm{M}^{2+}$ concentration, maximum/minimum permissible values of $\gamma_{2}$ may be computed from Equations 7, 11 and 12. If the value of $\gamma_{2}$ obtained from Equation 10 is within these limits then the reported $\left[\mathrm{M}^{2+}\right]_{\mathrm{f}}$ is reliable within the stated tolerance, else the measurement can be rejected. When cations are present other than those considered in this work $\left(\mathrm{Na}^{+}, \mathrm{K}^{+}\right.$, methylammonium, $\left.\mathrm{Ca}^{2+}, \mathrm{Mg}^{2+}\right)$, it is recommended to test the method in samples of known $\left[\mathrm{M}^{2+}\right]_{\mathrm{f}}$ to verify that the method does not yield, by chance, apparently perfect values of $\gamma_{2}$ but highly erroneous readings

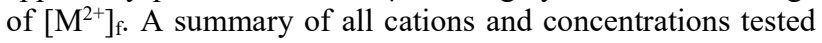
is provided in Table S- 8 . If working in $10 \mathrm{vol} \% \mathrm{D}_{2} \mathrm{O}$, an alternative set of indicator parameters must be used (Table S-2). Methanedisulfonate (KDS) may be used at acidic $\mathrm{pH}$; however, the method is not self-correcting for ionic strength or selfchecking and a recalibration of the ligand is necessary for every ionic background (Figures S-6 and S-8).

\section{CONCLUSIONS}

A method has been presented that permits the accurate determination of the free $\mathrm{Mg}^{2+}$ or $\mathrm{Ca}^{2+}$ concentration by ${ }^{1} \mathrm{H}$ NMR even in the presence of high concentrations of competitive background salts. The method is both self-correcting and selfchecking. By using indicator ligands of different charges, the method automatically compensates for the ionic strength of the sample and can thus be employed when the detailed ionic composition of a sample is unknown. The method also provides a representative ionic activity coefficient for the sample which can be used in further calculations as well as to judge the validity of the reported $\mathrm{M}^{2+}$ concentrations. The method may be readily applied using chemical shift imaging techniques to study the behavior of systems along $\mathrm{M}^{2+}$ gradients. Ligand binding constants and conformer distributions may be obtained this way in a highly efficient single-sample, singleexperiment manner. We anticipate that our methods will be employed wherever the $\mathrm{M}^{2+}$-dependent behavior of a system is of interest and amenable to study by solution state NMR.

\section{ASSOCIATED CONTENT}

\section{Supporting Information}

The Supporting Information is available free of charge on the ACS Publications website.

Correcting $\left[\mathrm{M}^{2+}\right]_{\mathrm{f}}$ for counterion pairing; establishment of the optimum $\mathrm{M}^{2+}$ gradient; effect of temperature on performance of $\mathrm{M}^{2+}$ indicators; effect of $\mathrm{D}_{2} \mathrm{O}$ on $\mathrm{M}^{2+}$ indicators; use of alternative reference compounds; additional $\mathrm{M}^{2+}$ indicator ligands; effect of $\mathrm{pH}$ and concentration on $\mathrm{M}^{2+}$ indicators; example calibration spectra of $\mathrm{M}^{2+}$ indicators; effect of interferent cations; direct calculation of $\left[\mathrm{M}^{2+}\right]_{\mathrm{f}}$ using Equations 3 and 8; simulated error plots; calculation of $\left[\mathrm{M}^{2+}\right]_{\mathrm{f}}$ in the presence of a complexing ligand; example NMR images to study ligand binding; snapshots from MD simulations of malate (PDF). 


\section{AUTHOR INFORMATION}

\section{Corresponding Author}

*E-mail: matthew.wallace@uea.ac.uk.

\section{Author Contributions}

M.W. conceived the concept of the paper and designed and performed all of the NMR experiments and data analysis. T.H. performed the molecular dynamics simulations under the guidance of J.A. M.W. wrote the paper with input from all authors.

\section{ACKNOWLEDGMENT}

M.W. thanks the Royal Commission for the Exhibition of 1851 for a Research Fellowship. T.H. is supported by the UKRI Biotechnology and Biological Sciences Research Council Norwich Research Park Biosciences Doctoral Training Partnership grant number BB/M011216/1. We are grateful for the use of the University of East Anglia (UEA) Faculty of Science NMR facility.

\section{REFERENCES}

(1) Thakur, B. R.; Singh, R. K.; Handa, A. K. Crit. Rev. Food Sci. Nutr. 1997, 37, 47-73.

(2) Tønnesen, H. H.; Karlsen, J. Drug Dev. Ind. Pharm. 2002, 28, 621-630.

(3) Christl, I. Environ. Chem. 2012, 9, 89-96.

(4) Fang, Y.; Al-Assaf, S.; Phillips, G. O.; Nishinari, K.; Funami, T.; Williams, P. A.; Li, A. J. Phys. Chem. B 2007, 111, 2456-2462.

(5) Kutus, B.; Buckó, A.; Peintler, G.; Pálinkó, I.; Sipos, P. Dalton Trans. 2016, 45, 18281-18291.

(6) Amburgey, J. C.; Huh, N. W.; Pedersen, L. G.; Hiskey, R. G. Bioorg. Chem. 1994, 22, 198-215.

(7) De Robertis, A.; Di Giacomo, P.; Foti, C. Anal. Chim. Acta. 1995, $300,45-51$.

(8) Lee, B. B.; Bhandari, B. R.; Howes, T. Colloids Surf. A Physicochem. Eng. Asp. 2017, 533, 116-124.

(9) Chung, H. J.; Ko, D. Y.; Moon, H. J.; Jeong, B. Biomacromolecules 2016, 17, 1075-1082.

(10) Miller, D. J. Colloid Polym. Sci. 1989, 267, 929-934.

(11) Maneval, J. E.; Bernin, D.; Fabich, H. T.; Seymour, J. D.; Codd, S. L. Magn. Reson. Chem. 2011, 49, 627-640.

(12) Wallace, M.; Iggo, J. A.; Adams, D. J. Soft Matter 2017, 13, 1716-1727.

(13) Somashekar, B. S.; Ijare, O. B.; Nagana Gowda, G. A.; Ramesh, V.; Gupta, S.; Khetrapal, C. L. Spectrochim. Acta A 2006, 65, 254260.

(14) Monakhova, Y. B.; Kuballa, T.; Tschiersch, C.; Diehl, B. W. K. Food Chem. 2017, 221, 1828-1833.

(15) Metcalfe, J. C.; Hesketh, T. R.; Smith, G. A. Cell Calcium 1985, 6, 183-195.

(16) Bar-Shir, A.; Gilad, A. A.; Chan, K. W. Y.; Liu, G.; Van Zijl, P. C. M.; Bulte, J. W. M.; McMahon, M. T. J. Am. Chem. Soc. 2013, 135, 12164-12167.

(17) Gupta, R. K.; Benovic, J. L.; Rose, Z. B. J. Biol. Chem. 1978, 253, 6172-6176.

(18) Lutz, N. W.; Bernard, M. J. Magn. Reson. 2018, 294, 71-82.

(19) Willcocks, J. P.; Mulquiney, P. J.; Ellory, J. C.; Veech, R. L.; Radda, G. K.; Clarke, K. J. Biol. Chem. 2002, 277, 49911-49920.

(20) Kozlyuk, N.; Sengupta, S.; Lupták, A.; Martin, R. W. J. Biomol. NMR 2016, 64, 269-273.

(21) London, R. E. In Annual Review of Physiology, 1991, pp 241258.

(22) Sarkar, D.; Shukla, R. K.; Gadgil, V.; Pramanik, A. Tetrahedron Lett. 2014, 55, 5925-5931.

(23) Chau, M.; Sriskandha, S. E.; Pichugin, D.; Thérien-Aubin, H.; Nykypanchuk, D.; Chauve, G.; Méthot, M.; Bouchard, J.; Gang, O.; Kumacheva, E. Biomacromolecules 2015, 16, 2455-2462.

(24) Salvati, A.; Lynch, I.; Malmborg, C.; Topgaard, D. J. Colloid Interface Sci. 2007, 308, 542-550.

(25) Wallace, M.; Adams, D. J.; Iggo, J. A. Anal. Chem. 2018, 90, 4160-4166.
(26) Baryshnikova, O. K.; Williams, T. C.; Sykes, B. D. J. Biomol. NMR 2008, 41, 5-7.

(27) Daniele, P. G.; Foti, C.; Gianguzza, A.; Prenesti, E.; Sammartano, S. Coord. Chem. Rev. 2008, 252, 1093-1107.

(28) Huynh, U. T. D.; Lerbret, A.; Neiers, F.; Chambin, O.; Assifaoui, A. J. Phys. Chem. B 2016, 120, 1021-1032.

(29) Kondoh, A.; Oi, T. Z. Naturforsch. A 1998, 53, 77-91.

(30) Ammann, C.; Meier, P.; Merbach, A. J. Magn. Reson. 1982, 46, 319-321.

(31) Trigo-Mouriño, P.; Merle, C.; Koos, M. R. M.; Luy, B.; Gil, R. R. Chem. Eur. J. 2013, 19, 7013-7019.

(32) Adams, R. W.; Holroyd, C. M.; Aguilar, J. A.; Nilsson, M.; Morris, G. A. Chem. Commun. 2013, 49, 358-360.

(33) Liu, M.; Mao, X. A.; Ye, C.; Huang, H.; Nicholson, J. K.; Lindon, J. C. J. Magn. Reson. 1998, 132, 125-129.

(34) La Mer, V. K.; Noonan, E. J. Am. Chem. Soc. 1939, 61, 14871491.

(35) Voice, P. J. J. Chem. Soc., Faraday Trans. 1 1974, 70, 498-505.

(36) Popov, K.; Rönkkömäki, H.; Lajunen, L. H. J. Pure. Appl. Chem. 2006, 78, 663-675.

(37) Brown, A. M. Comput. Methods Programs Biomed. 2001, 65, 191-200.

(38) Bränden, C. A.; Söderberg, B. O. Acta Chem. Scand. 1966, 20.

(39) The PyMOL Molecular Graphics System, Version 1.8. (Schrodinger, LLC, 2015).

(40) Case, D. A.; Ben-Shalom, I. Y.; Brozell, S. R.; Cerutti, D. S.; Cheatham, T. E.; III; Cruzeiro, V. W. D.; Darden, T. A.; Duke, R. E.; Ghoreishi, D.; Gilson, M. K.; Gohlke, H.; Goetz, A. W.; Greene, D.; Harris, R.; Homeyer, N.; Izadi, S.; Kovalenko, A.; Kurtzman, T.; Lee, T. S., et al. 2018, Amber 2018, University of California, San Francisco.

(41) Salomon-Ferrer, R.; Case, D. A.; Walker, R. C. Wiley Interdiscip. Rev. Comput. Mol. Sci. 2013, 3, 198-210.

(42) Danielczak, B.; Meister, A.; Keller, S. Chem. Phys. Lipids 2019, 221, 30-38.

(43) Pallagi, A.; Sebk, P.; Forgó, P.; Jakusch, T.; Pálinkó, I.; Sipos, P. Cabohydr. Res. 2010, 345, 1856-1864.

(44) Karki, I.; Christen, M. T.; Spiriti, J.; Slack, R. L.; Oda, M.; Kanaori, K.; Zuckerman, D. M.; Ishima, R. J. Phys. Chem. B 2016, 120, 12420-12431.

(45) Nancollas, G. H. J. Chem. Soc. 1956, 735-743.

(46) Bers, D. M.; Patton, C. W.; Nuccitelli, R. In Methods in Cell Biology, 2010, pp 1-26.

(47) Sun, M. S.; Harriss, D. K.; Magnuson, V. R. Can. J. Chem. 1980, $58,1253-1257$.

(48) McGuigan, J. A. S.; Kay, J. W.; Elder, H. Y. Prog. Biophys. Mol. Biol. 2017, 126, 48-64.

(49) Davies, C. W. J. Chem. Soc. 1938, 2093-2098.

(50) Banks, C. V.; Zimmerman, J. J. Org. Chem. 1956, 21, 14391440 .

(51) Wolfbeis, O. S.; Offenbacher, H. Sens. Actuators 1986, 9, 85-91.

(52) Opitz, N.; Lübbers, D. W. Sens. Actuators 1983, 4, 473-479.

(53) Rushing, T. S.; Hester, R. D. Polymer 2004, 45, 6587-6594.

(54) Partanen, J. I. J. Chem. Eng. Data 2012, 57, 3247-3257.

(55) Weiss, J. M.; Downs, C. R. J. Am. Chem. Soc. 1923, 45, 23412349.

(56) Monteiro, C.; Neyret, S.; Leforestier, J.; Hervé Du Penhoat, C. Cabohydr. Res. 2000, 329, 141-155.

(57) Kutus, B.; Dudás, C.; Peintler, G.; Pálinkó, I.; Sipos, P. Cabohydr. Res. 2018, 460, 34-40.

(58) Jaques, L. W.; Riesco, B. F.; Weltner, W., Jr. Cabohydr. Res. 1980, $83,21-32$

(59) De Robertis, A.; De Stefano, C. Talanta 1991, 38, 439-444.

(60) Kraszni, M.; Szakács, Z.; Noszál, B. Anal. Bioanal. Chem. 2004, $378,1449-1463$.

(61) Abraham, R. J.; Ashley Cooper, M. Magn. Reson. Chem. 2017, $55,837-845$

(62) Stouten, P. F. W.; Leeflang, B. R.; Van Eijck, B. P.; Kroon, J.; Mellema, J. R. J. Mol. Struc. 1988, 189, 65-80. 


\section{FOR TOC ONLY}

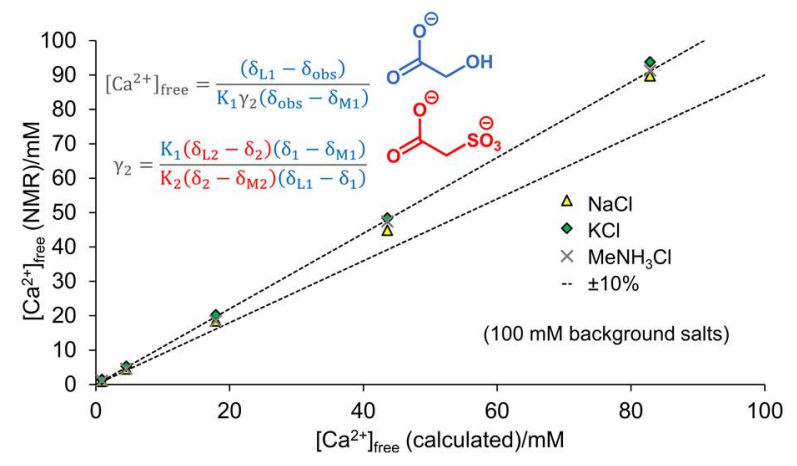

